\title{
Doing, Allowing, and Occasionalism
}

\author{
Sümer Şen \\ Faculty of Philosophy, Theology and Religious Sciences, Radboud University Nijmegen, Nijmegen, \\ $6500 \mathrm{HD}$, The Netherlands \\ email: sumersen83@gmail.com
}

(Received 31 December 2019; revised 5 February 2021; accepted 5 February 2021)

\begin{abstract}
In 'God, evil, and occasionalism' Matthew Shea and C.P. Ragland appeal to the Doctrine of Doing and Allowing to argue against Alvin Plantinga that occasionalism is morally worse than conservationism. In this article I critically examine their argument and conclude that it fails because it contains an equivocation or is unwarranted. I also offer a case against their position by, first, arguing that on none of three prominent accounts of doing and allowing God merely allows suffering.

Second, I develop the 'Epistemological-Equivalence Argument' in order to show that even if we grant such a distinction for God's acts, they would be morally on a par.
\end{abstract}

Keywords: God; occasionalism; conservationism; doing and allowing; indirect and direct causation; doing suffering; allowing suffering

\section{Introduction}

In 'Law, cause, and occasionalism', Alvin Plantinga engages in a discussion concerning the plausibility of views about divine causality. In doing so, Plantinga argues for the moral parity between 'weak occasionalism' and alternative views of divine causality (Plantinga (2016), 141). Weak occasionalism holds that human beings are merely the cause of their 'decisions, volitions, and undertakings (if indeed that relation is one of causation)', whereas God is the cause of the (outer) realization of those undertakings (ibid.). ${ }^{1}$ Accordingly, even though I may be the one who causes the decision to raise my hand, it is God 'who causes my hand to rise' (ibid.).

By broadening God's causal involvement in the world to such an extent, Plantinga makes God the direct cause of all kinds of suffering. To alleviate this worry, Plantinga argues that God's responsibility for suffering on weak occasionalism is not more problematic than on alternative views of divine causality, according to which God is the indirect cause of suffering. Plantinga's argumentation consists of an exposition of the respective views, to which he ultimately adds his observation that it is "hard to see how God is more responsible for causing the bad if he causes it directly than if he causes it indirectly' (ibid., 143). Plantinga's argument, then, appears to invite an antagonist to point out whence the moral disparity arises, as he fails to see it - despite having paid considerable heed.

(c) The Author(s), 2021. Published by Cambridge University Press. This is an Open Access article, distributed under the terms of the Creative Commons Attribution-NonCommercial-NoDerivatives licence (http://creativecommons.org/licenses/by-nc-nd/4.0/), which permits non-commercial re-use, distribution, and reproduction in any medium, provided the original work is unaltered and is properly cited. The written permission of Cambridge University Press must be obtained for commercial re-use or in order to create a derivative work. 
In 'God, evil, and occasionalism' Matthew Shea and C. P. Ragland accept Plantinga's invitation (Shea \& Ragland (2018)). They present a case against Plantinga by, first, arguing that his moral parity argument either commits the fallacy of equivocation or is guilty of an incoherency, both of which render his argument unconvincing (ibid., 275). Shea and Ragland then expound whence the moral difference arises by developing 'a positive argument, based on the doctrine of doing and allowing' (DDA), according to which doing suffering is morally worse than merely allowing it (ibid., 265). ${ }^{2}$ Their moral disparity argument merely deals with weak occasionalism and mere conservationism, as they believe that 'establishing that there is a morally relevant difference between occasionalism and mere conservationism is all that is needed' to show that Plantinga's crucial thesis is false (ibid., 276). In sum, Shea and Ragland claim that the moral disparity arises from the fact that God is doing suffering on weak occasionalism, whereas he is merely allowing it on mere conservationism.

In this article I extend the discourse by engaging with Shea and Ragland's disparity argument. I start by giving a brief overview of the prominent views of divine causality, in which I also explain the varieties of occasionalism that Plantinga introduces - as these will be germane to my engagement with shea and Ragland's argument. Then I examine Shea and Ragland's disparity argument and argue that it lacks any warrant and thus is unconvincing. Even though this critique does undermine the epistemic ground of their argument, it does not disprove their central thesis: the moral disparity claim. To do away with this deficiency, I devote the remaining parts of the article to showing why the moral disparity claim is false. My strategy will be twofold: first, I will argue that on mere conservationism God should not be considered to be merely allowing suffering, by showing that when prominent (metaphysical) accounts of doing and allowing are applied to mere conservationism, God appears to be doing suffering. Hence, even if we are willing to accept the DDA, and thus that doing suffering is morally worse, the argument cannot get off the ground as God appears to be doing suffering on mere conservationism anyway.

Second, I argue that even if we assume, for the sake of argument, that the doing and allowing distinction parallels weak occasionalism and mere conservationism, and thus that God is merely allowing suffering on mere conservationism, there is no moral difference between them. By presenting an analogy to both views and expounding it, I extend and consolidate Plantinga's previously quoted claim that there appears to be no reason why one should regard mere conservationism morally superior to or less problematic than weak occasionalism (ibid., 143). ${ }^{3}$

\section{The issue of divine causality}

Philosophers and theologians have disputed the precise nature of God's causal involvement in the world. The discussion is mainly centred on the distinction between direct and indirect causal activity. ${ }^{4}$ At the minimalist side we have mere conservationism, which is said to have received the least adherence in history, on which God's causal involvement is held to a minimum (Ott (2009), 37; Freddoso (1991), 555). According to mere conservationism God has created secondary causes, beings endowed with the ability to actively cause things in the world, and has limited his causal involvement to conserving the world at every moment of its existence. This also encompasses the existence of objects that reside in the world. Thus, when secondary causes cause an action, such as raising a hand, they are the direct causes thereof. God, on the other hand, the primary cause, is a mere indirect cause of that action, 'by virtue of His conserving action' (Freddoso (1991), 554).

Mere conservationism, furthermore, denies that 'God is directly involved in the causality of non- divine causes', and thereby assigns independence of some sort to the world 
and reserves a more remote role to God (Valicella (1996), 339). This independence does not, however, mean that the world can do without God; on the contrary, without God's conserving activity neither the world as a whole nor secondary causes in particular can endure.

At the maximalist side there is occasionalism, according to which there is no cause but God in the world. God is thereby maximally involved in the occurrence of events in the world (ibid.).

Occasionalism denies, in the face of common sense, the existence of secondary causes and thus maintains that there are no 'non-divine causes'. Every act that I appear to be causing, moreover, such as raising my hand, is rather directly, that is, without an intermediate cause, and solely caused by God.

Everything besides God may thus be described as inert beings, not able to engage actively with the world.

In between these two extremes, there is concurrentism, which has been very popular in history such that it is regarded as the majority view among the scholastics (Platt (2020), 33). Like mere conservationism, concurrentism acknowledges the existence of secondary causes that directly cause their actions. Concurrentism approximates to occasionalism, however, in that it also holds that God is directly causing everything in the world. On this picture, then, God cooperates with secondary causes to the effect that, besides secondary causes causing their actions directly, God causes their action directly as well (Valicella (1996), 339).

In the present article, I will, like Shea and Ragland, leave aside concurrentism and focus on mere conservationism and occasionalism. Although Shea and Ragland concur with the characterization of mere conservationism given above, they are concerned with weak occasionalism, which differs from occasionalism as being described above (Shea \& Ragland (2018), 266). When arguing that 'there is a significant disparity between occasionalism and mere conservationism with respect to God's causal role in suffering.', shea and Ragland refer to weak occasionalism (ibid., 279, 281). As noted in the introduction, weak occasionalism holds that there are secondary causes, which are capable of merely causing 'decisions, volitions, and undertakings (if indeed that relation is one of causation)' (Plantinga (2016), 141). On weak occasionalism God is the direct cause of everything except the undertakings of secondary causes. The version of occasionalism described above coincides with what Plantinga calls 'strong occasionalism', according to which God is the sole cause in reality, and thereby also causes decisions of human beings (ibid., 138).

\section{The moral objection and Shea and Ragland's DDA argument}

Having seen a general overview of the prominent views of divine causality, we now may look at Shea and Ragland's argument for their moral disparity claim. Given the significance of the DDA to their argument, I will call their argument 'the DDA Argument'. Shea and Ragland introduce the DDA Argument against the background of 'the moral objection' to weak occasionalism, which Plantinga first addressed in his article (Shea \& Ragland (2018), 267; Plantinga (2016), 141). The moral objection to occasionalism may be described as the intuitive repulsion to the attribution of horrible acts to a "perfectly loving and perfectly good' God (Plantinga (2016), 139). Plantinga himself expresses the moral objection to weak occasionalism by way of example as follows:

I decided to rob a bank; in the course of the robbery I shot someone. God does not cause me to decide to rob the bank or to shoot the guard, but he does cause all of the motions of my limbs, including my shooting the guard, and he also causes the guard's injury or death. Does this not make God the cause of evil? (ibid., 141) 
In this regard, Plantinga introduces a distinction between evil and bad. The former denotes a morally wrong decision and the latter 'bad situations or states of affairs - someone's suffering, or being treated unjustly' (ibid., 142). Accordingly, only beings that cause evil decisions perform evil acts. And since God does not cause decisions of secondary causes on weak occasionalism and since he himself does not have evil decisions, God thereby does not cause the evil on weak occasionalism. God does do the bad on weak occasionalism, however, as he is taken to be the sole and direct cause of everything besides decisions, which involves the quoted examples by Plantinga. Plantinga intuits that God's direct causation of the bad still appears to be at odds with his moral character: 'God is not the cause of evil, but he is the cause of the bad, and is that not bad enough?' (ibid.). This intuitive 'repulsion', as I call it, is what amounts to the moral objection.

The DDA Argument, on the other hand, constitutes an additional and distinct objection. The DDA Argument is based on the commonly assumed DDA. The DDA, that is, the doctrine of doing and allowing (not to be confused with the DDA Argument), holds that doing suffering is morally worse than merely allowing it. The moral superiority of allowing suffering to doing it appears to be an important strand of common-sense morality. We commonly do not think 'that it would be no worse to murder to get money for some comfort such as a nice winter coat than it is to keep the money back before sending a donation to Oxfam or Care', even though we appear to be allowing many to die by not donating (Foot (1994), 281; Woollard (2012), 449). By developing an argument based on the DDA, Shea and Ragland seem to seek a theoretical expression of the moral objection and thus exceed the intuitive level of argumentation (Shea and Ragland (2018), 279). As a result, the DDA Argument purportedly has the advantage of enabling shea and Ragland to explain and justify the intuition underlying the moral objection more forcefully.

In order to grasp the function of the DDA Argument more fully, it is noteworthy that Shea and Ragland offer the argument explicitly to show that what they have identified as the 'NRD' (No-real-difference) principle is false (ibid.). The NRD-principle holds that 'there is no morally relevant difference between directly and indirectly causing the bad' (ibid., 271). This, then, implies that the DDA Argument also serves to show that mere conservationism is morally superior to strong occasionalism, since the latter not only accommodates God's direct causation of the bad but contends in addition that God directly causes the evil.

\section{Shea and Ragland's two tasks}

Advocates of the DDA ought to complete two separate tasks, which parallel the two claims comprised by the DDA (Woollard (2012), 449; Draper (2005), 254). As the DDA fundamentally holds that acts can be divided into two classes, one being acts of doing and the other acts of allowing, DDA-advocates need to explicate the distinction between acts of doing and allowing. This most plausibly means that they must explicate the features an act has to have in order to be counted as doing rather than merely allowing (and vice versa).

The second task consists in showing that doing suffering is morally worse than allowing it, which is the DDA's second claim. This task stands on its own, and a failure to successfully complete it does not necessarily imply a failure of the first one. For it might be that we successfully show that there is a metaphysical difference between acts, some being acts of doing and others of allowing, without there being a difference in their moral status. Moreover, many if not all critics of the DDA admit that there are acts of doing and allowing, but assert that there is no relevant moral difference (Woollard \& Howard-Snyder (2016)).

As the DDA Argument assumes the truth of the DDA, we may reasonably expect Shea and Ragland to have fulfilled both tasks. It appears, however, that they do not even 
attempt to fulfil either of them. ${ }^{5}$ They explain in footnote 25 that they simply have no ample space 'to provide a detailed formulation and defence of the doctrine' (Shea \& Ragland (2018), 283). This deficiency can also be sensed from their concise and unclear explication of the DDA. Shea and Ragland initially seem to identify doing with acts and allowing with omissions, as they purport that, "The Doctrine of Doing and Allowing (DDA) centres on the moral difference between acts and omissions' (ibid., 276). But then they identify acts and omissions with 'action' and 'inaction', respectively - as they explain that 'A simple, rough formulation of the doctrine can be put in terms of action and inaction' (ibid.).

When discussing objections to the DDA Argument, shea and Ragland remark that an omission or inaction does not mean 'doing absolutely nothing': 'the DDA does not claim that the morally significant difference is between causing something directly versus having no causal involvement whatsoever (i.e. doing absolutely nothing with respect to the chain of events that terminates in suffering), even though the doctrine is couched in terms of inaction or omission' (ibid., 278). Rather than explaining what these sorts of act do consist in, they note that the DDA centres on 'alternative kinds of causal participation' (ibid.). It is, however, not made easy upon the reader to understand what is meant by these 'alternative kinds of participation', that is, acts, omissions, actions and inactions.

To advance our understanding of the difference, shea and Ragland do provide an example of what concrete acts would amount to acts of doing and acts of allowing: 'it seems plausible to say that there is a morally relevant difference between killing a terminally ill patient who wishes to die versus letting such a patient die from natural causes, all other things being equal' (ibid.). One thus performs an act or an action when one kills a patient, and thereby is doing suffering, whereas one performs an omission or an inaction when one lets a patient die from a disease, and thereby is merely allowing suffering. The additional claim of the DDA is that the former is morally worse and harder to justify than the latter (Woollard (2012), 448). This is what Shea and Ragland must refer to when they speak of 'the DDA'.

Shea and Ragland show this clarificatory and argumentative parsimoniousness also when dealing with the justification of the DDA. They state that the 'central claim' of the DDA, 'that there is a morally relevant, intrinsic difference between doing and allowing evil', is, plausibly, 'both intuitive in its own right and consonant with Christian ethics' (ibid.). Thus, although the DDA Argument surpasses the moral objection by giving a theoretical principle, that is, the DDA, to ground the intuitiveness of the objection, it appeals to intuition as well to render the theoretical principle plausible.

Having explained the general structure of the DDA Argument and the DDA, we may consider how the steps of the DDA Argument are organized. The DDA Argument first identifies God's causation of the bad on weak occasionalism as doing it, as 'God is the sole direct cause of all the suffering in the world, it is impossible to say that God allows any of these events to occur; instead, God is always doing the bad' (ibid.). It then contends that on mere conservationism, on the other hand, 'God truly permits suffering because God does not directly cause it, but rather allows us to cause it' (ibid., 277). The argument then introduces the DDA, and thereafter concludes that weak occasionalism is morally worse than mere conservationism.

\section{Evaluating the DDA Argument}

Is Shea and Ragland's exposition of the DDA Argument sufficient to render it compelling? Pondering upon the terms they deploy to advance our understanding of doing and allowing, like 'act', 'omission' or 'inaction', reveals that they are barely helpful to render what is intended more intelligible. The terms that are used for clarification are themselves highly 
ambiguous. Why is it that that the one who lets a patient die is performing an inaction, even though he seemingly performs an action by, for instance, sitting and watching the patient's death? Surely sitting and watching someone seem to be actions.

What it most striking, however, is that Shea and Ragland seem to consider the addition of a criterion for drawing the line between 'actions' and 'inactions' superfluous. It must then be that Shea and Ragland lean on our intuitive or common-sense conception of such terms or concepts, which does not assume any rigid definition or criterion. Surely, we could argue, common sense dictates that the one who kills the patient is performing an action. And the same goes for the one who merely lets him die and an inaction. This is how things are commonly conceived of. Opting for this interpretation, however, makes Shea and Ragland vulnerable to the objection that, after all, the DDA Argument is not a proper theoretical expression of the moral objection and forms barely an advance over it. Given that this interpretation remains the most plausible one, the DDA Argument itself appears to be residing at the intuitive or common-sense level, which we had already reached by the moral objection.

We cannot expect Shea and Ragland, or anyone, to prove every (implicit or explicit) point they defend and thus take no points for granted. Assuming things is inevitable, especially when word-limits are in place. So it is not problematic that shea and Ragland assume things without presenting their justification in general. The problem is that Shea and Ragland appear to be contending that their limited clarification, nevertheless, succeeds in rendering 'The general idea of the DDA . . . clear enough for (their) purposes' (ibid.). Their main purpose, in using the DDA, moreover, was to 'show that NRD is false' and thus that 'there is a morally relevant difference between God's direct and indirect causation of suffering' (ibid., 276, 265). It should, however, be clear now that their exposition of the DDA Argument does not suffice to realize its assigned function. As arguments acquire their worth by the extent to which they compel the conclusion sought, this observation amounts to a serious problem.

\section{The bigger problem of the DDA Argument}

Furthermore, shea and Ragland's reliance on the common-sense notion of the DDA gives rise to a bigger problem, which I deem fatal to their argument. The problem in question concerns the application of the DDA across human and divine cases. It appears that for their argument to be logically valid, Shea and Ragland must assume that the meanings of 'doing' and 'allowing' stay significantly the same when applied to both human and divine acts. This assumption, however, is clearly false. Shea and Ragland cleverly anticipate this objection and respond to it. After having worked out this objection in more detail, I will discuss their response and explain why it is not compelling.

Let's consider a reconstruction of the DDA Argument to see 'the bigger problem':

1. Acts resolve into two kinds: acts of doing and acts of allowing (doing-allowing distinction $)^{6}$

2. Doing suffering is morally worse than allowing suffering (the DDA)

3. On weak occasionalism God is doing suffering and on mere conservationism God is allowing suffering

4. Thus, weak occasionalism is morally worse than mere conservationism (from 1, 2, and 3)

To render the argument valid, and avoid an equivocation, we must assume that the meaning of 'doing' and 'allowing' remains the same throughout the argument. This, however, cannot be the case. As noted previously, mere conservationism holds that God's indirect 
causation of our actions means that he is the one who facilitates the exercise of our causal power to such a degree that the absence of his indirect causation or conserving act would prevent us from acting. We are thus highly dependent upon the service that God provides to do what we do.

To identify that conception of allowing with our common-sense conception of allowing is unreasonable. It is far from what we appear to be thinking of when we identify everyday human acts as acts of allowing. By way of example, it would be highly noncommonsensical to assume that the one who let a patient die was nevertheless providing the disease with the power to put the patient to death. Or was providing the patient with the necessary (biological) means to stay long enough alive so that the disease could do its work - which is in fact what God does on mere conservationism.

It is much more common and intuitive to assume that one's absence or non-existence would still have resulted in the patient's death. One could have been locked up, flying in the air, or even been dead. It would have made no difference to the fate of the patient. The patient's death was not dependent upon the person or his actions, and thus would have transpired even if one would have been deprived of his agency. This rather seems to be what common sense dictates.

From this is becomes clear that there is a grandiose disanalogy between God's doing and allowing and our doing and allowing, giving rise to what we may call the disanalogy-objection'. The disanalogy-objection prevents Shea and Ragland from transferring the intuitiveness of the DDA in the case of humans to God's case without further argumentation, because the DDA comes to have a different meaning in divine cases than in human ones. The (commonsensical) meaning of 'doing' and 'allowing' in premises 1 and 2 is significantly different from their meaning in premises 3 and 4 . 'Significantly different' here denotes their independent truth values, that is, the commonsensical DDA may be true while the one referring to divine acts may at the same time be false.

However, this objection does not show the falsity of premise 4. In other words, the disanalogy objection does not constitute a positive argument for the moral equivalence between God's doing and allowing. It is rather an undercutter of premise 4's warrant. This shows that Shea and Ragland simply do not have a legitimate ground for the premise, which of course does nothing to show that it is false.

\section{Shea and Ragland's response to the disanalogy-objection}

Luckily, the second of the two objections that Shea and Ragland consider to the DDA Argument coincides roughly with the disanalogy-objection. ${ }^{7}$ So let us consider their response to it. They formulate it as follows:

the occasionalist can argue that there is a crucial disanalogy between God and human beings which blocks the straightforward application of the DDA to the situation involving God and suffering. Our intuitions about human cases of acts and omissions do not transfer to God because God's causal involvement in worldly events is significantly different from our own.

When humans allow suffering, they make no positive causal contribution to the chain of events, and they also have limited knowledge of the circumstances and consequences involved. (ibid., 277)

Their response to this objection is twofold. First, they point at the threat of having to 'think of God as a consequentialist', which 'most theist will not want to endorse', if we thwart the application of the DDA to him (ibid., 278). To this we may simply point out that the denial of 
the DDA in God's case is compatible with the denial of consequentialism. We can still hold that God's intentions, will, and means are indispensable to the moral evaluation of his acts. So in its current (underdeveloped) form, this response is not compelling.

Second, Shea and Ragland remark that the DDA does not claim that the morally significant difference is between causing something directly versus having no causal involvement whatsoever (i.e. doing absolutely nothing with respect to the chain of events that terminates in suffering)' (ibid.). The DDA is purportedly 'meant to highlight the difference between alternative kinds of causal participation' (ibid.). And as Shea and Ragland rightly point out, we may distinguish God's acts on the basis of his different kinds of causal participation, one being direct and the other indirect.

It is hard to see, however, how this response addresses the objection. The objection does not deny that we may claim that God's acts may involve different 'kinds of causal participation'. It rather denies that we can deploy the intuitive plausibility of the DDA in everyday human cases as a warrant for the application the DDA in divine cases. Even though human acts and divine acts may both be suitable for a division based on the kind of causal participation they involve, the difference in kinds of causal participation they may involve is too great to use the warrant of the DDA in the human case for the DDA in the divine case.

Although Shea and Ragland remark that they are aware of significant differences between the human and divine realm, they appear to be regarding the realms to be sufficiently similar for a transfer of the DDA from the human realm to the divine one. They admit that 'there is something unsettling about God knowing ahead of time about all the suffering that will occur (if we assume the truth of Molinism), creating and sustaining the causal regularities needed to produce it, and choosing to allow it to happen' (ibid., 278). They also remark that 'the acts/omissions distinction is not exactly parallel in the case of God and human beings', but add that it is 'applicable enough to pose a problem for occasionalism, which is unable to hold that God truly permits suffering (as opposed to directly producing it)' (ibid.).

Yet the foregoing explication of what both human acts of allowing and God's conserving act amount to undermines their claim that the distinction is 'applicable enough'. Furthermore, as noted, the next section will consider a prominent account of doing and allowing, and will show that according to none of them can God be considered to be merely allowing suffering on mere conservationism. This will serve as an additional argument against Shea and Ragland's claim that the human and divine realm are sufficiently similar.

One might question what other way there is at Shea and Ragland's disposal to ground the DDA Argument, and thus to properly 'show why there is a morally relevant difference between God's direct and indirect causation of suffering', if it cannot be a direct transfer of our moral intuition in human cases. I believe that another viable option in cases where such an immediate transfer is not legitimate is using 'the contrast strategy' (Kagan (1988), $5,10)$. The contrast strategy aims to determine whether a factor is morally relevant by considering (at least) two cases in which everything is equal except that one case contains the concerning factor and the other does not. If the cases are given different moral evaluations, the difference is explained by the moral significance of the factor.

By utilizing the contrast strategy, Shea and Ragland could offer two cases, occurring in the human realm, in which suffering occurs, and which are equal in all respects except in the sort of causation that is involved. If it follows with sufficient clarity that the case in which indirect causation is involved is morally less bad than the one in which direct causation is involved, we would be given reason to regard the direct causation of suffering morally worse than the indirect causation thereof. The problem, thus, is not so much with using human cases in order to derive conclusions about divine ones, it is 
rather the immediacy with which this is done. Moreover, I believe that utilizing the contrast strategy will conversely show that our moral intuition finds God's doing and allowing of suffering to be morally equivalent. I will present such an argument in the last section.

Thus far I have focused on Shea and Ragland's DDA argument and have examined whether it fulfils the purpose they assigned to it. I concluded that the DDA Argument is not valid in its current presentation and not 'positive' in the sense that it provides a warrant for the conclusion. In the next section I will argue for the moral equivalence or parity between God's doing and allowing of suffering, by (i) fulfilling the first task shea and Ragland, as advocates of the DDA, should have fulfilled, namely to present accounts that explicate the doing-allowing distinction. I will examine whether God's causal role as being depicted on mere conservationism can be regarded as merely allowing on any of three prominent accounts. I will argue that none of those accounts leaves room for such a rendering. As this distinction concerns the first main claim of the DDA, the DDA cannot be applied to God if the distinction is not in place. In the last section, I will (ii) present a contrast strategy, of which I spoke earlier, which does not depend upon (i), to the effect that it is compatible with there being acts of doing and acts of allowing in God's case. The contrast argument will argue that despite the assumed metaphysical difference between God's acts, there can be no moral difference between them. Both (i) and (ii) serve to show that Shea and Ragland's claim that mere conservationism is morally superior to occasionalism is false.

\section{Three accounts of the doing-allowing distinction}

As noted before, this section consists of an application of three prominent accounts of the doing-allowing distinction to God's acts. The goal is not to critically evaluate the coherency of the accounts, but rather to see whether they reveal that God merely allows suffering on mere conservationism.

\section{The counterfactual account}

Counterfactual accounts work by hypothesizing states of affairs that lack a crucial feature of the agent in the actual state of affairs, and ask whether the upshot in the actual state of affairs would have obtained in the hypothetical state of affairs (Woollard (2012), 451; Kagan (1989), 94). This crucial feature might be the existence of the agent or his agency. If some harm had befallen a patient even if I had always been non-existent or failed to express my agency at that moment, I will be qualified as merely allowing the harm. If, on the other hand, my non-existence or lack of agency had entailed the absence of the harm, I am qualified as doing it.

Shea and Ragland appear to be rightly pointing out that every theistic account of divine causality is on a par with regard to the counterfactual dependence of suffering on God. All those accounts agree that 'if God had not created and conserved agents and all of their effects (or had not created anything at all), then suffering never would have occurred' (Shea \& Ragland (2018), 272). This means that on the counterfactual account God is always doing suffering, even on mere conservationism. The counterfactual account, then, does not provide the means to distinguish between God's acts or different 'kinds of causal participation' in order to apply the DDA to him.

\section{The causal-sequence account}

The other prominent account in the field is the causal-sequence account, attributed to Philippa Foot. Foot's account is scattered over several works, which provide parts of 
the whole (Foot (1967); Foot (1994)). Furthermore, she leaves some issues unclear that seem to suggest incoherencies in her account. I believe, however, that drawing on Fiona Woollard's presentation of her account will give us the most charitable construal, even though this might not most accurately represent Foot's ideas (Woollard (2012), 449-450).

For Foot the doing-allowing distinction is grounded upon the way an agent is causally related to a sequence leading to an upshot: 'the moral character of an action is on occasion affected by the position of the agent in the causal nexus' (Foot (1985), 25). If an agent has (i) originated 'a fatal sequence', by initiating it while it was previously non-existent, or has (ii) sustained it by, providing the necessary conditions without which it would have terminated, he counts as doing the upshot, that is, harm (Norcross (1994), 14; Foot (1985); Woollard (2012), 450). If, on the other hand, the agent has

(iii) forborne to prevent a pre-existing sequence from running, by not providing an obstacle to it, or

(iv) enabled a pre-existing sequence to proceed, by removing an obstacle to it, he counts as merely allowing the upshot (Woollard (2012), 450). ${ }^{8}$

Foot presents two cases in order to make her distinction more intelligible. In the first case, 'Rescue I', we are on our way to rescue five people and get notified about a 'lone individual', 'who also needs rescuing from some other disaster' (Foot (1994), 282). Rescuing that one person would prevent us from rescuing the five, so we continue our journey and 'leave him to die' (ibid.). In the second case, 'Rescue II', we are again on our way to rescue five people. But this time 'the lone individual is trapped (do not ask me how) on the path. If we are to rescue the five we would have to drive over him' (ibid., 283).

Foot remarks that the way we are related to the fatal sequence leading to the lone individual's death in Rescue I is morally permissible. We merely allowed the suffering by forbearing to prevent a pre-existing sequence from running (iii). Running over the individual in Rescue II, however, is not permissible: 'we cannot, however, drive over him in order to get to them (the five people)' (ibid.). This would be originating a previously non-existent fatal sequence (i) without legitimate reason: 'We cannot originate a fatal sequence, although we can allow one to run its course' (ibid.).

Relating it to our main discussion, it should be noted that, throughout his article, Plantinga assumes a libertarian or non-determinist framework and shea and Ragland seem to follow him in that respect. Within this framework, mere conservationism implies that the causal sequence that God initiated at the moment of the creation of the world does not contain the acts of secondary causes, some of which are evil (Plantinga (2016), 130, 131). From this we can conclude that the first form of doing (i), originating a sequence, does not hold for God on mere conservationism.

Yet God has been sustaining those fatal sequences, initiated by secondary causes, by means of his conserving act. God has been conserving secondary causes with their causal power at every moment of their existence. This conserving act is indicative of God's active use of his powers. So when someone decided freely to choose to kill an innocent person, God conserved him in existence. And when that person had taken steps to realize his will and pulled the trigger to kill an innocent person, God again provided the conditions that were needed for the fatal sequence to endure long enough to terminate in suffering. This means that the second form of doing (ii), sustaining a sequence, certainly holds for God. Thus it follows that God is regarded as doing suffering on mere conservationism by the causal-sequence account. 


\section{The 'Most of the Things He Could Have Done' account}

The last account I deem prominent and worthy of discussion is Jonathan Bennett's the 'Most of the Things He Could Have Done' account (Woollard (2012), 451; Woollard \& Howard-Snyder (2016)). ${ }^{9}$ Bennett identifies the distinction between doing and allowing with the distinction between positive and negative facts (Bennett (1998), 88). According to the 'Most of the Things He Could Have Done' account one allows an upshot if an explanation of its occurrence merely requires a negative fact about one's behaviour (ibid., 88-89). You do something, on the other hand, if the upshot's occurrence requires a positive fact about your behaviour. A fact is negative if it is related to most of the things one can do. A fact is positive, on the other hand, if it is related to the least of the things one can do (ibid., 91-92).

Bennett explains how we can determine what kind of fact to appeal to by looking at the totality of ways the agent could have behaved (ibid., 91; Woollard \& Howard-Snyder (2016)). If I kill someone by shooting him, a positive fact explains the upshot and I count as having done the suffering - since most of the ways I could have behaved, such as firing all the bullets into the air or walking away without shooting, would not have resulted in the suffering at stake. I could have done plenty of other things that would not have the killing as a consequence.

Allowing a patient to die from a disease, on the other hand, is part of most of the ways I could have acted, which would nevertheless have resulted in the patient's death. Few actions of the ways I could have acted would have prevented him from dying, such as providing him with medication.

As God is regarded as omnipotent, such that he is capable of realizing all logically possible actions, an infinity of actions seems to be at his disposal. This would mean that for every act God performs, we could say that it is not part of most of the ways he could have acted. It seems then when God performs any act, he is doing it on Bennett's account. On a Molinist world-view, according to which God knows how an agent would act under any given circumstance, God was aware of plenty of other options that would not have resulted in the suffering of this world or any suffering whatsoever. God could have simply refrained from creating a world with humans. He could have created a world with merely various planets without any intelligent life. God could have created a world with robotic beings that did not possess any freedom and carried out all of God's commands. Ultimately, as God is considered to be genuinely free, he was not necessitated to create the current world or anything whatsoever.

God's act to create this world and conserve it in existence, then, was not most of the ways he could have acted. This means that God's involvement in the occurrence of suffering in the world denotes a positive fact and thus, on the 'Most of the Things He Could Have Done' account, God counts as doing the suffering on mere conservationism.

To sum up, in this part I have looked at a number of prominent accounts of the doingallowing distinction. It appears that on all these accounts, God's conserving act is described as a doing rather than allowing. This gives us reason to suppose that the fundamental claim of the DDA, that there are acts of doing and acts of allowing, does not apply to divine acts. As these accounts were formulated and developed within the context of human acts, and were attempts to capture our moral intuitions in everyday acts, this conclusion also strengthens the point that we cannot immediately transfer our intuition concerning the DDA in human cases to divine ones. One may object that I have not considered all accounts that have been developed and thus fail to prove my point. The constraints I am faced with do not allow me to present them all. Yet, I believe that the least my case shows is that it is not at all evident whether one can formulate a coherent and intuitively plausible account that shows that God's conserving act is a form of allowing. This places a burden on the adversary to offer such an account. 
In the following section I will elaborate on an argument that Shea and Ragland construed as one of the arguments Plantinga might have offered. I will call the argument 'the Epistemological-Equivalence Argument'. It is important to know that the Epistemological-Equivalence Argument assumes, for the sake of argument and contrary to what the foregoing part aimed to show, that there is a metaphysical distinction between God doing versus allowing suffering. Thus, the argument agrees with Shea and Ragland that God is doing suffering on weak occasionalism and merely allowing it on mere conservationism. The Epistemological-Equivalence Argument will show that there is nevertheless no moral difference between those two sort of acts in God's case. This means that the second claim of the DDA, that doing suffering is morally worse than merely allowing it, does not apply to God either.

\section{The Epistemological-Equivalence Argument for moral parity}

When attempting to interpret Plantinga's case for the moral parity between weak occasionalism and mere conservationism, Shea and Ragland formulate an argument that I deem very promising. The argument holds that 'as long as God's knowledge of suffering is the same on both views, then it makes no moral difference what kind of causal contribution God makes to the production of suffering' (Shea \& Ragland (2018), 273). Given Molinism, God's knowledge encompasses all subjunctive conditionals, and thus all direct or indirect outcomes of his possible actions. As Shea and Ragland rightly point out, this implies 'that any two situations with the same divine knowledge and the same result will yield the same divine responsibility, whether the connection between $\mathrm{X}$ and $\mathrm{S}$ is direct or indirect' (ibid.).

Shea and Ragland criticize the argument for being unwarranted as they claim that the argument's main premise 'is precisely what needs to be proved in order to show that there is moral parity between occasionalism' and mere conservationism (ibid.). Thus, one is not entitled just to assume that premise, but rather ought to ground it. In the remainder of this section, then, I will develop the argument, calling it the 'Epistemological-Equivalence Argument' (EEA), by offering a ground for its main premise, 'that any two situations with the same divine knowledge and the same result will yield the same divine responsibility, whether the connection between X and S is direct or indirect' (ibid.). In doing so, I do away with the aforementioned deficiency and provide the EEA with a reasonable ground.

The argument deploys the aforementioned contrast strategy. It presents two cases, which respectively form an analogy with God's involvement in the occurrence of suffering on mere conservationism and weak occasionalism. As explained earlier, on mere conservationism God supplies secondary causes with the necessary means for expressing their agency. This is, as we have seen, a great service that God provides.

Let us consider a case within the human realm that approximates to mere conservationism. To have an accurate analogy, we need at least three secondary causes that are causally apt, that is, able to actively cause or be subjected to causal actions. 'The Killer', analogous to human secondary causes, serves as the agent who causes the suffering directly, such that there is no other human secondary cause in between him and the suffering. ${ }^{10}$ 'The Victim', analogous to secondary causes as well, is subjected to this suffering and thus serves as the causal patient. 'The Provider', analogous to God, on the other hand, causes the suffering merely indirectly, to the effect that there is a human secondary cause in between him and the suffering. The Provider causes the suffering indirectly by providing the necessary means for the suffering to be realized.

As the story goes, the Victim made it a habit to swear at the Killer upon encountering him. This infuriated the Killer, to the degree that he was convinced that he could solve the situation and rid himself of his anger solely by killing the Victim. Yet, the Killer was a 
very dependent and physically poor being. Even though he was able to some degree to do what he wanted, he failed to do so in significant respects, such as the means to stay physiologically alive. Although the Killer had the capability to pull a trigger by himself, he was not capable of singlehandedly securing all of the conditions that were necessary for him to cause the killing directly. These conditions included a life support machine (ECMO), due to the malfunctioning of his heart and lungs, food to obtain sufficient minerals and thereby stay alive, firearms training, an actual firearm, bullets, and a chauffeur and vehicle in order to travel to the Victim's house.

The Provider, on the other hand, we are told, was powerful enough to provide the Killer with these means. He had, in fact, been providing the Killer with the means to stay alive for some while. When encountering the Provider, the Killer tells him about his plans to kill the Victim. The Provider, as good as his character is, condemns these plans severely and advices him to change his mind. The Killer, however, urgently requests the Provider to provide him with the (additional) means to carry out his plan, reminding the Provider that he had provided similar conditions in the past when the Killer went out to hunt birds. It should be emphasized that the Provider knew very well that without this service, the Killer could not kill the Victim and cause the suffering. Yet, as the Provider believed that the expression of one's free will and causal power has intrinsic value, he ultimately agreed to do exactly what the Killer had asked.

An important detail is that the Provider also provided the Victim with the necessary physiological means, such as food and an ECMO-machine, to undergo the suffering. The Victim likewise lacked the power to remain alive and was in urgent need of the Provider's service. Moreover, the Provider could have chosen to refrain from facilitating the Victim to stay alive shortly after being informed about the Killer's plan, and thereby would prevent him from facing the Killer's immoral act. Yet, the Provider chose to remain consistent and proceeded to offer the Victim the services he used to offer.

After ample preparation had been carried out, the Killer was brought to the Victim's house. Not knowing what was about to happen, the Victim was reading a book in his front yard. Just before the Victim noticed the Killer, and presumably would start swearing at him, the Killer pointed his gun at him and shot. The bullet struck the Victim's heart and he died slowly at the scene.

Even in this case, moreover, for the Victim to feel the pain in his body, he must be kept alive for some time, by means of the ECMO-machine and an additional heart massage. Moreover, his nervous system must also be kept intact to some degree. If the nervous system fails to work properly, the pain may not be transmitted to the Victim's consciousness. The Provider was also present at the scene and knew that he was the only one capable of providing these conditions. He could have refrained from doing so, thereby immediately ending the suffering, or preventing the Victim from undergoing any suffering at all - by refraining from keeping him alive a millisecond after the bullet hit him. Yet, for the sake of consistency, the Provider chose to act otherwise and kept the Victim alive for a considerable time. The Provider thereby knowingly caused the Victim's death to be preceded by serious suffering.

This scenario seems to sufficiently approximate to mere conservationism. On weak occasionalism, on the other hand, the difference would be that the Killer and the Victim have no causal power whatsoever to realize their undertakings, not even to pull a trigger. The provider then would not cause the suffering indirectly, by providing them with the necessary means. Rather, he would be doing everything directly. Both the Killer and the Victim would be described roughly as physically paralysed beings. When shooting the Victim, then, the Killer's finger would be placed on the trigger by the Provider, with the finger of the Provider above it. The firearm would shoot merely due to the pressure exerted upon the trigger by the Provider and the bullet would travel to the 
Victim's body due to the Provider pushing it with sufficient force. And the ECMO-machine would be replaced by the Provider's direct effort to make the Victim's heart beat and make his nervous system transmit the pain. I believe that this as close as the analogy with weak occasionalism gets.

We must now question whether we ought to evaluate the moral status of the Provider in the first and second case differently. Is the Provider in the first case really less bad than in the second? It seems obvious to me that the Provider's involvement in the death of the Victim in the first case is as bad as his involvement in the second - even though their acts related to the Victim's death through different forms of causation. As it follows that the moral evaluation of the Provider in the two cases is the same, we are warranted to conclude that God's direct causation of suffering, as on weak occasionalism, is not worse than his indirect causation thereof, as on mere conservationism. This clearly proves the EEA's claim and disproves Shea and Ragland's disparity claim.

\section{Objections to the EEA}

One may critique the EEA by pointing out that it is a form of the contrast strategy and thus faces the problems associated with it. ${ }^{11}$ When discussing ethical principles, philosophers sometimes attempt to prove that a factor is morally significant by presenting two cases that are identical in all respects except that in one the factor is present and in the other absent. Shelly Kagan explains the contrast strategy nicely as follows:

One offers a pair of cases that differ only in terms of the factor in question. If we judge the two cases to be morally different, it is argued, this difference must arise from the different values of the given factor (everything else being held constant), and so the factor is shown to be morally relevant. If we judge the cases to be similar, on the other hand, despite the variation in the given factor, this shows that the factor is not actually morally relevant after all. (Kagan (1988), 5-6)

Thus, when considering whether, for instance, an evil intention tied to an evil act is morally significant, we may contrast two cases in which the same person performs the same evil act and all other things are equal, expect that in one the person has an evil intention and in the other he has not. If our moral evaluations of the cases are not different, the contrast strategist will conclude that evil intentions are not morally significant - since if they were morally significant, the moral evaluations would differ. ${ }^{12}$

It seems indeed that the EEA contrasts two cases that differ only with respect to the sort of act that is involved, one doing and the other allowing, and aims to show that this difference does not give rise to a moral difference. From those two cases it concludes that there is no case in which there is such a moral difference. The EEA presents the case of the Killer and the case of the Provider, in which their causal involvement is different, and concludes that there is no moral difference between them or their actions. Based upon this particular conclusion, the EEA concludes that there are no divine cases in which the DDA holds.

Accordingly, a critic of the EEA may reject it by holding that 'it is sometimes permissible to allow a certain harm it would have been impermissible to do' (Fitzpatrick (2012), 184). This allows for the concession that the DDA 'does not imply that in all such pairs it will make a difference, and so it is compatible with the claim that in some contexts it will not, even where all else is equal between the cases' (ibid.). The DDA, then, would be contextsensitive and not apply in all cases, such as the one described above.

The first problem that arises when one opts for the context-sensitivity objection is that it places a heavy burden on its defender. Since now it is contended that the DDA does not always apply, the defender of the DDA will be assigned a third task, which consists in 
formulating when and why the DDA holds. Shea and Ragland would then have to fulfil this third task, in addition to the first and second task, to have an adequate case against the moral parity claim. In this regard, we may weaken the conclusion of the EEA, by holding that it merely makes the conclusion plausible or gives reason to believe it until the opposite is shown. This would still mean that the defender of the EEA is epistemically superior to the one who endorses Shea and Ragland's case. Shea and Ragland, then, would be burdened with the task to offer divine cases in which the DDA does apply.

It might, moreover, be plausible to render the DDA context-sensitive in the case of humans, as many human features are variable or such that they can constitute an excuse. As William Mann puts it:

We sometimes excuse human agents for not intervening when they might have because we think that the cost of intervening to them would have been inordinately high. We sometimes loathe and sometimes pity those who fail to intervene because of their stupidity, cowardice, venality, callousness, or other sorts of character flaws. (Mann (1988), 207-208) ${ }^{13}$

The major problem, however, is that it seems hard to see how the DDA can be contextsensitive in the case of God. The context-sensitivity of the DDA must rest upon a variable factor, such that there arises a difference between cases that explains why the DDA holds or not. This factor, however, cannot be related to the nature of God, since he is traditionally assumed to be immutable. God, on the theistic conception, will always be good, almighty, and all-knowing. The difference cannot lie in his causal involvement in the occurrence of worldly suffering either, since this remains constant on mere conservationism. Thus, the explanation for why the DDA would or would not apply has to be related to a factor external to God. This can lie in the act of secondary causes, of which the realization is facilitated by God, or the secondary causes themselves, which God conserves.

Concerning acts, we may divide them into moral and amoral ones, of which the latter refers to acts that are not apt for moral evaluations and should not be confused with nonmoral ones. ${ }^{14}$ Within these subcategories, however, acts must be on a par with each other, that is, acts are either subject to moral evaluation or not. The critic of the EEA may purport that the DDA is applicable to divine amoral acts, without being applicable to moral ones. But that leaves the argument unharmed, as it is precisely concerned with the moral evaluation of God's acts. The only option that remains for the critic is to contend that the DDA applies to some moral acts. But, as I have also pointed out, it is not clear why it would apply to one moral act and not to the other, since the one is as moral as the other.

Concerning secondary causes, we may say that some of them have more causal power in comparison with others, such that the potential extent of their causal activity is greater. Yet, this does not reduce their dependence upon God. Neither does it reduce God's indirect causation qua conservation. So this differentiating feature is extraneous to our discussion. These considerations thus seem to deprive the critic of any ground to substantiate the recourse to the context-sensitivity objection.

Ultimately, one could offer a disanalogy-objection to the EEA by arguing that the human cases do not adequately reflect God's causal involvement on either view. ${ }^{15}$ Yet, it seems that the only respect in which the cases differ from the divine ones, is in the degree of causal involvement. It seems evident that God's involvement exceeds the human ones', and thus is much greater. So, if the conclusion holds for the human cases in the EEA, it must then a fortiori hold in divine ones. This gives us reasonable ground to transfer the conclusion regarding the human cases to the divine ones. 


\section{Conclusion}

In this article I have argued that Shea and Ragland have not fulfilled their purpose to show that there is a moral disparity between mere conservationism and weak occasionalism. I explained that their argument fails in at least two ways, one having to do with its adequateness and utility, and the other having to do with its validity. In order to disprove their disparity claim, I extended my case in a twofold way. First, I assumed the coherence of three doing-allowing distinctions and applied them to God, after which it appeared that on none of those accounts is God merely allowing suffering.

Second, I assumed that there was, after all, a genuine doing-allowing distinction in God's case and questioned whether there was a moral difference between them. I developed the Epistemological-Equivalence Argument in order to show that there could be no moral difference between God's acts of doing and allowing suffering. ${ }^{16}$

\section{References}

Bennett J (1998) The Act Itself. Oxford: Oxford University Press.

Calder T (2018) The concept of evil. In Zalta EN (ed.), The Stanford Encyclopedia of Philosophy (Summer 2018 Edition). Available at https://plato.stanford.edu/archives/sum2020/entries/concept-evil/.

Draper K (2005) Rights and the doctrine of doing and allowing. Philosophy \& Public Affairs 33, 253-280.

Fitzpatrick WJ (2012) The doctrine of double effect: intention and permissibility. Philosophy Compass 7, 183-196.

Foot P (1967) The problem of abortion and the doctrine of double effect. Oxford Review 5, 5-15.

Foot P (1985) Morality, action, and outcome. In Ted Honderich (ed.) Morality and Objectivity. New York: Routledge, pp. 23-38.

Foot P (1994) Killing and letting die. In Bonnie Steinbock and Alastair Norcross (eds), Killing and Letting Die. New York: Fordham University Press, pp. 280-289.

Freddoso A (1991) God's general concurrence with secondary causes: why conservation is not enough. Philosophical Perspectives 5, 553-585.

Kagan S (1988) The additive fallacy. Ethics 99, 5-31.

Kagan S (1989) The Limits of Morality. Oxford: Oxford University Press.

Mann WE (1988) God's freedom, human freedom, and God's responsibility for sin. In Morris TV (ed.) Divine and Human Action: Essays in the Metaphysics of Theism. Ithaca, NY: Cornell University Press, pp. 182-210.

Norcross A (1994) Introduction to the second edition. In Steinbock B and Norcross A (eds), Killing and Letting Die. New York: Fordham University Press, pp. 1-23.

Ott W (2009) Causation and Laws of Nature in Early Modern Philosophy. Oxford: Oxford University Press.

Plantinga A (2016) Law, cause, and occasionalism. In Bergmann M and Brower JE (eds) Reason and Faith: Themes from Richard Swinburne. Oxford: Oxford University Press, pp. 126-144.

Platt A (2020) One True Cause: Causal Powers, Divine Concurrence, and the Seventeenth-Century Revival of Occasionalism. New York: Oxford University Press.

Quinn W (1989) Actions, intentions, and consequences: the doctrine of doing and allowing. The Philosophical Review 98, 287-312.

Shea M and Ragland CP (2018) God, evil, and occasionalism. Religious Studies 54, 265-283.

Vallicella W (1996) Concurrentism or occasionalism? American Catholic Philosophical Quarterly 70, 339-359.

Woollard F (2012) The doctrine of doing and allowing I: analysis of the doing/allowing distinction. Philosophy Compass 7, 448-458.

Woollard F and Howard-Snyder F (2016) Doing vs. allowing harm. In Zalta EN (ed.) The Stanford Encyclopedia of Philosophy (Winter 2016 Edition). Available at https://plato.stanford.edu/archives/win2016/entries/doingallowing/.

\section{Notes}

1. Plantinga excludes the discussion of beings other than humans, which is why the description of weak occasionalism solely includes human beings as secondary causes (Plantinga (2016)). The discussion between Plantinga, Shea and Ragland and myself revolves around suffering or evil that is commonly qualified as moral evil, as opposed to natural evil, see Calder (2018). It should be noted that our discussion narrows its focus by merely looking at human suffering or evil, although various positions presented may easily accommodate nonhuman moral agents. 
2. Henceforth the doctrine of doing and allowing will be referred to as 'the DDA'.

3. Plantinga does not utilize the term 'mere conservationism' but rather speaks of 'secondary causalism' (Plantinga (2016), 134). As mere conservationism is presumably a form of secondary causalism, his quoted claim implies that there is no moral disparity between weak occasionalism and mere conservationism.

4. I follow Shea and Ragland in omitting deism and focus merely on theistic conceptions of divine causality (Shea \& Ragland (2018), 280).

5. In his review, Matthew Shea remarks that they did not intend to fulfil the two tasks.

6. One could read this premise also as 'Acts resolve at least into two kinds', thereby allowing for other types of acts. 7. The second objection Shea and Ragland consider not only draws on the difference in causation between humans and God but also on the difference in the scope of knowledge. The disanalogy-objection disregards the latter and focuses on the former.

8. There appears to be a counter-intuitive element in the causal-sequence account's assumption that the preexisting sequence had to be already harmful when the agent related itself to it by one of the four acts (Woollard (2012), 450; Quinn (1989), 298). I allow the omission of this assumption, and grant, for the sake of charitability, that the characteristic of allowing is the independence of the upshot on the agent. This means that on the sequence account what matters for allowing is whether 'the sequence is appropriately independent of the agent's behaviour' (Woollard (2012), 450). I believe, furthermore, that Foot's remarks in a later article provide room for this interpretation: 'in the case of allowing, a train of events must already have started or be on the horizon; an agent who could stop or prevent it does not do so, and therefore allows it to go on' (Foot (1985), 24). The threat of the sequence-account becoming reducible to the counterfactual one by making this adjustment will be ignored. This adjustment, however, does nothing to show that God is, in fact, allowing harm on mere conservationism. It would, conversely, corroborate the view that God is doing the harm, as no causal sequences in the world, let alone fatal one, are 'appropriately independent' of God.

9. Bennett's account may also be subsumed under counterfactual accounts, but as I find his demarcation criterion between doing and allowing distinctive and original, I deem it appropriate to deal with his account separately.

10. The qualification of 'human' is needed here to call the causation properly direct, since we may say that nonhuman objects, such as bullets, are secondary causes as well.

11. I thank Matthew Shea for pointing this objection out to me.

12. Conversely, if the moral evaluations were to differ, this would still be a contrast strategy, but one with a different conclusion. This is meant to emphasize that the contrast strategy is not merely meant to show that something is morally insignificant, as the examples given might tempt one to think. It can serve both directions. 13. Mann concludes from this fact that the DDA is not applicable to God. Shea and Ragland reject his argument by appearing to construe his argument as denying the antecedent. Yet, I believe that Shea and Ragland's construal is wrong. The conditional is not 'If one may be stupid, a coward or the like, then the DDA applies to his actions. This would commit Mann to the belief that the DDA applies to animals, beings that can have the features cited in the antecedent, as well. It seems more likely that Mann believes that acts of animals are amoral. A more charitable construal would be to transpose the antecedent and consequent, such that the conditional becomes: 'If the DDA applies to one's acts, then he may be stupid, a coward or the like'. Mann, accordingly, is denying the consequent for God, which makes his argument a modus tollens.

14. 'Amoral' is meant to denote that which is not suited for moral evaluation. 'Amoral' may apply to objects or beings, such as stones, and also acts, such as those of plants and more controversially of animals. 'Immoral', on the other hand, operates within the morally apt category, and denotes the opposite of what is regarded morally right. 'Immoral' may similarly apply to things and acts. Stones are amoral, whereas stealing for fun is immoral. It is beyond the scope of my article to argue for the moral-amoral distinction.

15. I thank Carla Rita Palmerino for drawing my attention to this objection.

16. I would like to thank Matthew Shea for reading and reviewing earlier versions of this article. His insightful comments have contributed greatly to its quality. I would also like to thank Carla Rita Palmerino for reviewing the article and assisting me in the process. I am also very thankful to Nazif Muhtaroğlu for providing his views on the EEA. My thanks are due to Marian, a librarian at the University of Groningen Library, for finding and sending me a book chapter. Finally, I thank my dear friends Rachid and Charif for reading the article and showing great interest in the topic.

Cite this article: Şen S (2022). Doing, Allowing, and Occasionalism. Religious Studies 58, 505-521. https://doi.org/ $10.1017 /$ S0034412521000056 